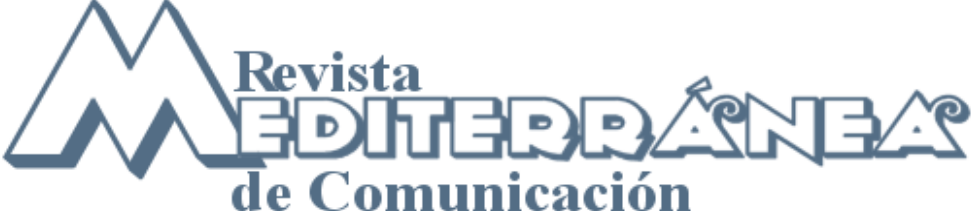

\section{Ecología de la comunicación e interacción social}

\author{
Joan Costa
}

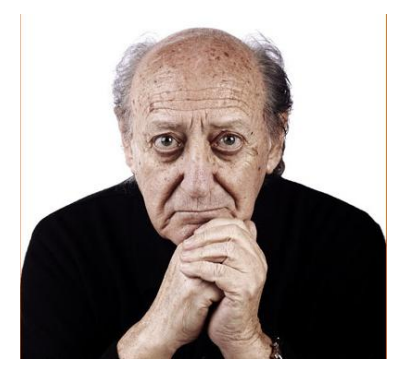

\begin{abstract}
JOAN COSTA es autodidacta, comunicólogo, sociólogo, diseñador, investigador y metodólogo. Creador de Costa punto cero Editor. Es uno de los fundadores europeos de la diencia de la Comunicación Visual. Consultor corporativo, asesor de empresas en por la Universidad Jaume I, España, y por la Universidad Siglo 21, Córdoba, Argentina. Ha dirigido más de 400 programas de Comunicación, Imagen, Identidad Corporativa y cambios culturales para empresas e instituciones de diferentes países. Ha impartido cursos y seminarios en la Universidad Louis Pasteur (Estrasburgo) y Universidad Tecnológica de Compiègne (Paris); Universidades Anáhuac, lberoamericana, Intercontinental, Nacional Autónoma Metropolitana, Tecnológico de Monterrey y Universidad de Las Américas (México), entre otras.
\end{abstract}

\section{Sistema mediático y sistema social}

Son los mass media los que han creado la sociedad de masas, la cultura de masas y la publicidad de masas. La lógica publicitaria "masiva" es solidaria de la lógica mass mediática. Ellas juntas han determinado una evidente inclinación hacia los media de mayor alcance, los de efectos cuantitativos más espectaculares y simultáneos en el espacio y en el tiempo, cuya audiencia, por tanto, era más numerosa y cuyo coste por impacto y cobertura ofrecía las máximas ventajas. Era el modelo que triunfaba en los años 60 y 70. Las profecías macluhanianas sobre el poder absoluto de los medios electrónicos y, en consecuencia, el descenso de los medios tradicionales (el cartel, el anuncio, el impreso: Gutenberg, en fin), contribuyeron a reforzar el modelo mass mediático en detrimento de otras posibilidades que se basarían precisamente en las condiciones contrarias, es decir, en las segmentaciones selectivas y en valores cualitativos: lo que hemos llamado micro media.

Pero cuando Marshall McLuhan declaró la "guerra de las galaxias", enfrentando la galaxia Gutenberg (el texto impreso) y la galaxia Marconi (la comunicación a la velocidad de la luz) hizo una predicción, como sabemos, errónea. No fue la televisión la que se opuso al impreso, ni la visión profusa del discurso televisivo la que se opuso a la lectura lineal del texto. No es el medio electrónico el que se opone al medio impreso. Es la Imagen la que se ha impuesto en todos los medios. Es la Imagen, y no el medio difusor. Es el mensaje icónico -un "mensaje de imágenes"-, multiplicado, diversificado, propagado por el formidable aparato del conjunto de los medios visuales y audiovisuales y también de la tecnología digital interactiva.

En nuestra era de la "opulencia comunicacional" no hay tales enfrentamientos totalitarios. Los media de comunicación no se anulan entre sí: coexisten. Y se reparten los poderes. Lo que caracteriza la opulencia de las comunicaciones es el hecho cuantitativo, esto es, la coexistencia 
múltiple de los diferentes medios y técnicas; la proliferación y ubicuidad de estos media; las interacciones tecnológicas que fecundan nuevas formas y nuevos media. Y en consecuencia, la enorme circulación de estímulos y mensajes, y la propagación de los diferentes lenguajes y códigos de comunicación... lo que, en síntesis, lleva a la cultura del espectáculo y a la saturación.

Ese es exactamente el mismo modelo del consumo, el de la "sociedad afluente" (Galbraith). La afluencia es la abundancia y la diversidad; la concurrencia; la proliferación desbordante de bienes y productos. No sería posible hablar de "sistema consumista" si éste no fuera afluente y plural, de la misma manera que no se podría hablar de "cultura de masas" si ésta no fuera masiva y global, opulenta y exuberante. No estamos en la guerra de las galaxias de los media, sino en la Galaxia de la Imagen en un cosmos comunicacional. En ella, todos los media son sus difusores y sus propagadores. Es la fabulosa maquinaria de la industria de la imagen.

Por consiguiente tenemos que ver los nuevos medios y técnicas emergentes desde esta posición abierta que acepta que todos estos recursos coexisten, en principio o potencialmente, en pie de igualdad unos con otros. El error es verlos exclusivamente desde la posición mediáticopublicitaria y por relación a ella, cuando deben ser considerados desde la sociología de la comunicación. Muchos publicitarios se preguntan si los "nuevos recursos técnicos y mediáticos, y los nuevos soportes son alternativos o sucedáneos de la publicidad", y la cuestión ya está sesgada en la misma formulación de la pregunta. Si analizamos el contexto en el que esta pregunta se manifiesta se comprende que "alternativos a la publicidad" significa a la publicidad tradicional: mass mediática, al anuncio, a las campañas. Esta posición desde el terreno publicitario en el que se formula la pregunta es un punto de partida sesgado, ya que la cuestión tiene que trasladarse, desde ahora, al marco diverso y global de las comunicaciones. Para el cual este problema no existe. En segundo lugar, tal planteamiento supone que se refiere a la publicidad de difusión por los media masivos, y excluye otros media selectivos, los micro media personalizados e interpersonales y los self media, como las redes sociales.

El razonamiento es sencillo, y podemos empezar a responder la pregunta de más arriba partiendo de estos parámetros:

1. Determinados medios y técnicas pueden ser alternativos a la publicidad, en la medida que los anunciantes no los están utilizando: no se trata de medios y técnicas propiamente "publicitarios", en el sentido tradicional del término. La idea de que "publicitar es hacer público" es demasiado general para profundizar de modo pertinente en el problema. Hay otros modos de "hacer público" que no son en sí mismos publicitarios: la noticia periodística, los bandos municipales, las señales e indicaciones urbanas, los paneles del tráfico, internet, etc. Ciertamente, estos elementos no son en su naturaleza publicitarios, pero son portadores de mensajes, de información. Son medios de comunicación social y, como tales, es evidente que por una parte pueden ser alternativos y por otra parte pueden ser autónomos en tanto que "medios" desde su condición de informativos. Hay que distinguir, pues, de entrada entre medios y técnicas publicitarios, comerciales e informativos. Por consiguiente, pueden ser alternativos a la publicidad si con ellos se consiguiera el mismo efecto que los anuncios. Pueden no serlo, por tanto, si buscan otras metas -como la información de utilidad pública- y utilizan otros recursos específicos.

2. Pueden no ser alternativos a la publicidad, pero pueden no ser excluyentes de ésta. Las promociones, el marketing directo, los patrocinios o los eventos, no son en sí mensajes publicitarios directos, ni son "anuncios", sino una clase de acciones que requieren algún modo de ser comunicadas o bien que ellas mismas son acciones de comunicación. 
3. Pueden ser alternativos al anuncio tradicional e incluso a los mass media, cuando no se trata de mensajes prefabricados y bien embalados, sino de otra clase de publicidad, como el histórico logotipo luminoso gigante recubriendo por entero la Torre Eiffel parisina, que es un ejemplo de acciones "publicitarias" sin anuncios, sin mensajes argumentales, imágenes, campañas ni medios masivos. ¿Son sucedáneos de la publicidad o son otra forma más diferente, más sorpresiva de publicidad, y tal vez por eso mismo, más efectiva en determinadas condiciones? Sin embargo, lo que es realmente importante no es tanto lo que preocupa a la profesión publicitaria tradicional sobre los medios, soportes y técnicas que pueden ser sus concurrentes, sino la lógica contraria: la de llevarles a considerar si no son sus complementarios... Lo que se necesita es tratar de penetrar en la estructura del problema: entonces nos daremos cuenta de que en su conjunto lo que se está produciendo debido a la agobiante saturación publicitaria es un movimiento ecológico de la comunicación bien evidente: un desplazamiento de los lugares de encuentro entre el mensaje publicitario y el consumidor. Una ecología en sentido propio, que tiene lugar en el interior del ecosistema global de las comunicaciones.

\section{Ecología de la comunicación}

La ecología de la comunicación es la ciencia de las relaciones e interacciones que existen entre las diferentes especies de actividades de comunicación dentro de un sistema social disperso en un territorio. Es una ciencia estadística de los medios de comunicación, de los mensajes que transportan, de las relaciones entre ellos y con los públicos y la sociedad, y cómo son utilizados unos más que otros en un momento dado, tanto por las agencias como por los individuos, e incluso en síntesis, cómo unos predominan sobre otros alterando así los valores de un campo que es, por naturaleza, evolutivo y cambiante.

Tales son los problemas que plantea la existencia de redes diversas, de modos distintos de comunicación -como los citados self media-, unos en relación con los otros y todos ellos en relación con los individuos. Así, pues, la ecología de la comunicación parte de la idea de que es posible realizar una descripción de la actividad humana en términos de comunicación, en función de la naturaleza de los mensajes enviados en una repartición estadística de éstos.

El hombre, consumidor de mensajes en el sentido más amplio -que incluye el consumo publicitario-, posee unas capacidades receptivas limitadas. Esta limitación de base es uno de los condicionantes que coinciden con la aparición de nuevos medios y técnicas publicitarios y parapublicitarios ( $\mathrm{y}$ también nopublicitarios, lo cual va bastante más allá del egocéntrico below the line, término que tanto satisface a las agencias). El núcleo de la cuestión estriba en cuáles medios son privilegiados en un espacio significativo de tiempo y cuáles son rechazados; cuáles insinúan su declive y cuáles emergen amenazándoles.

Este es, por tanto, un problema múltiple, que contiene en sí mismo -o que está provocando- una situación "ecológica", que por su complejidad y sus interacciones, es de hecho, multipolar y epifenoménica. (Epifenómenos son fenómenos diferentes que se producen al mismo tiempo y parecen interrelacionados, aunque no existan relaciones causales entre ellos).

La problemática actual de la saturación publicitaria está envuelta en diversos fenómenos, más o menos vinculados entre sí, pero que juntos en sus interrelaciones constituyen situaciones nuevas en diferentes campos pero de algún modo coincidentes. Cuando observamos estos fenómenos y los relacionamos entre sí ya vemos hasta qué punto existen o no entre ellos 
relaciones fuertes; nos damos cuenta de su lógica subyacente. Un análisis de este tipo nos lleva a establecer un cuadro analítico de fenómenos interrelacionados.

- Por una parte, emergen nuevos medios y técnicas de comunicación publicitaria o parapublicitaria (es una de las preocupaciones del aparato, es decir, del business).

- Simultáneamente, hay un descenso evidente de la efectividad de los medios y técnicas hegemónicos tradicionales, al mismo tiempo que éstos aumentan en número y en presencia de los competidores, y se encarecen las tarifas.

- Los resultados de ambos fenómenos en conjunto son la densidad estadísticamente creciente de soportes, mensajes y medios: la "opulencia comunicacional" (Moles).

- Este aumento progresivo de los medios y técnicas supone una diversificación y una densificación de las estimulaciones publicitarias, e implica una competición implacable entre ellos (ecología de la comunicación).

- Tal competición engendra una presión y una saturación de estímulos en lucha para acceder a la percepción de los individuos, y esta saturación llega a bloquear los canales sensoriales humanos de recepción, tal como demuestran los estudios ya clásicos de Shannon.

- La respuesta a una situación de saturación es cualitativa, selectiva, porque el ser humano no puede permanecer bloqueado, cerrado a las comunicaciones de su entorno. Necesariamente, se produce entonces la necesidad de elegir.

— En los procesos de elección intervienen diferentes factores correlacionados:

- la coincidencia relativa entre mensaje-producto e interés o grados de disposición del individuo ante cada estímulo publicitario;

- la originalidad o inversamente, redundancia del mensaje (novedad,repetición, desgaste);

- el placer, la satisfacción o la información obtenidas (cantidad de gratificación psicológica por tiempo, atención y esfuerzo invertidos);

- el tiempo (unidades temporales) requerido por cada mensaje: su duración, que implica una inversión temporal individual variable;

- la atención, requerida al receptor (concentración relativa, esfuerzo, tiempo, etc.);

- el esfuerzo intelectual relativo que supone la comprensión de un mensaje más o menos difícil.

Pero un nuevo problema surge en el centro de la ecología comunicacional. Es el de cómo las nuevas tecnologías modifican aspectos fisiológicos de los individuos (el teléfono móvil, Internet, iPod, iPad, etc.); aspectos perceptuales que afectan al sentido de la visión; aspectos psicológicos como la socialización de la tecnología; aspectos antropológicos como los cambios de las costumbres; aspectos sociales y culturales, en fin.

\section{Provocar la reacción y provocar la interacción: dos estrategias comunicacionales}

La irrupción de la tecnología interactiva de comunicación -televisión interactiva, telefonía móvil, videoconferencia, Internet, blogs y todo el instrumental digital-, han decantado los medios masivos, instrumentos unidireccionales por naturaleza, en bidireccionales y dialogantes entre sus 
destinatarios. Con ello se pone de manifiesto la compatibilidad de los media: mass media, micro media, inter media y self media.

Recordemos que, igual como la teoría de la propaganda y la publicidad tomaron el behaviorismo como modelo -en el sentido invasivo y manipulatorio del término-, también tomaron de los medios de masas su esencialidad como emisores unilaterales, esto es, difusores. Por su parte, el esquema clásico de la teoría matemática de la comunicación (Shannon, 1948) propuso un modelo explicativo tan esquemático, que es de hecho un fragmento mínimo del proceso, que no es lineal sino circular.

La relación entre un emisor que afecta a un receptor por medio de un mensaje que es transferido por un canal de izquierda a derecha (expresividad del modelo) pone en evidencia que este modelo, por ser un fragmento solamente de la interacción donde ella misma no cabe, lo que de él se infiere corresponde más exactamente a la difusión unidireccional que a la intercomunicación.

Este comentario es episódico, sobre todo cuando la televisión interactiva ya es un hecho. Pero es útil aquí señalar que el esquema de Shannon es propio de un ingeniero de telecomunicaciones que se interesa por el canal pero no por lo que hace la gente con él ni por los contenidos que se intercambian. No es este el interés de un sociólogo, por supuesto, ya que éste hubiera procedido privilegiando la interacción y los efectos. Por una parte, Shannon desarrolló una serie de hipótesis sobre el soporte material de la telecomunicación, y sus hallazgos son diversos, desde la cuestión de los códigos a los de tipo cuantitativo: cantidad de información, capacidad del canal en bits por segundo, saturación del canal, etc. Un psicosociólogo hubiera privilegiado los aspectos relativos a la relación entre los comunicantes; hubiera dirigido su atención a los elementos inmateriales y cualitativos: contenidos de los mensajes, "sentido" de la información, interpretaciones, reacciones, etc. $\mathrm{Y}$ en cierto modo, es eso precisamente lo que profundiza la sociología de la comunicación al lado de la tecnología.

El esquema gráfico del proceso comunicativo no hubiera sido lineal como el de Shannon, sino circular, y con esto, el proceso habría quedado claramente mostrado en su totalidad en tanto que "intercomunicación": hubiera destacado la retroacción o feed back, que es la sustancia misma de la intercomunicación.

De hecho, los sucesivos desarrollos del modelo de Shannon, hechos por los sociólogos y teóricos de la comunicación, incluyeron de inmediato en dicho esquema, los grafos que representan el "retorno" y el proceso más desarrollado, incluyendo, por ejemplo, la correspondencia entre los códigos de los comunicantes, las desviaciones entre intención del emisor e interpretación del receptor, etc.

Con todo esto lo que debemos poner de relieve es precisamente la necesidad irreversible de interactividad como el flujo que une a emisores y receptores, que a su vez son productores, manipuladores, conservadores y transmisores de mensajes. Es la interactividad que el behaviorismo y la publicidad mediática unidireccional dejaron a un lado, y que la tecnología ha acabado por imponer. Enzensberger había escrito con lucidez, en 1979, que los medios llamados "de comunicación" como la radio y la televisión, no estaban al servicio de la comunicación, ya que no admiten ninguna influencia recíproca entre el emisor y el receptor, reduciendo cualquier posibilidad de feed back al nivel mínimo que permite el sistema. Este estado de cosas -advertía entonces el autor- no puede ser de ningún modo justificado por razones técnicas, ya que desde el 
punto de vista técnico no existe ninguna contradicción de principio entre el emisor y el receptor. Si existe esta separación entre ambos, las razones serían exclusivamente políticas, es decir, preservar, al nivel de la industria del entretenimiento de masas, la división social, distinguiendo la línea de demarcación que separa a los productores y a los consumidores, los emisores y los receptores. Pero otra razón que se puede añadir es que el Poder económico, político, mediático, confesional, etc., descubrieron en la comunicación mediática un instrumento potente de control social.

Efectivamente, el sistema de diseminación de informaciones desde un punto central hegemónico a la masa social, no es de hecho un sistema de "comunicación social" -si bien el enunciado es elegante, ¿o eufemístico?-, sino un sistema de difusión masiva. La unidireccionalidad y la irreversibilidad de las tecnologías "de difusión masiva" no facilitan la comunicación, ya que si partimos del hecho comunicativo como intercambio simbólico de bienes e informaciones -lugar de un mensaje y de una respuesta-, la supresión de uno de los dos polos del canal comunicacional implica la instauración de un monopolio: la superioridad del que habla sobre el que escucha. Por esto he evocado el control social encubierto en la fórmula "comunicación social".

El ejemplo de la interlocución telefónica (Shannon) -o también el de la televisión por cable-, y por otra parte, los ejemplos de la radiodifusión y la televisión de antena, ponen de manifiesto la coexistencia en la práctica de dos tecnologías: una tecnología reactiva (propia de la publicidad tradicional) y una tecnología interactiva, que la publicidad se ha apresurado a utilizar.

En la modalidad reactiva, que es propia de los medios tradicionales de masas, la estructura de su funcionamiento es del tipo homeostático, o sea, que las variaciones internas y externas del médium apenas consiguen que éste se ajuste a los impulsos de lo aleatorio o de la coyuntura, ya que su naturaleza tiende a perpetuarse, es decir, a mantener su autoestabilidad a través de un comportamiento rutinario o conservador en tanto que "aparato" (exactamente como el aparato publicitario). Los ejemplos más claros son los de la radio y la televisión broadcast, que practican la difusión por diseminación (¿inseminación?) desde un punto central privilegiado que controla las redes hasta sus millones de terminales humanos de recepción. En la tecnología reactiva no hay propiamente respuestas "al medio" en el pleno sentido del término ("contestar", "contestación", en su doble acepción coloquial y crítica), sino que todas las posibilidades se reducen a poder escoger entre unas mínimas alternativas preestablecidas: cambiar de canal o desconectar.

En la tecnología interactiva, por el contrario, la estructura de su funcionamiento no es del tipo homeostático, sino cibernético, es decir, realimentado y sistémico, y en consecuencia modificado por el binomio emisor-receptor. La relación ya no es más la del transmisor central y el receptor pasivo, o la del productor y el consumidor, sino de interlocutores e interacciones. En la tecnología interactiva el intercambio de informaciones realiza una auténtica intercomunicación propiamente dicha, a nivel asimismo interpersonal. Por el contrario, llamemos la atención sobre los videojuegos y la informática con sus programas especializados, cuya capacidad de feedback es nula, a pesar de lo que puede aparentar, porque la libertad de la reacción siempre está limitada por las variables del programa. Sólo se puede hablar aquí de una "ilusión de interacción", que puede parecer "creativa" porque es un juego... y como tal está regido por sus propias leyes y no por la voluntad libre y espontánea de sus usuarios.

La Comunicación es una ciencia autónoma. En tanto que ciencia, "sólo se ocupa de lo general', y es por eso que se adapta a tanta variedad de análisis y aplicaciones particulares. Se 
basa en principios universales y en la facultad intrínseca de socialización del ser humano en el marco de una tecnociencia ya inexcusable. 